\title{
Dietary Intervention with Nutrient-Dense, Portion-Controlled, Functional Foods Improve Blood Pressure in Adults
}

ISSN: 2640-9208

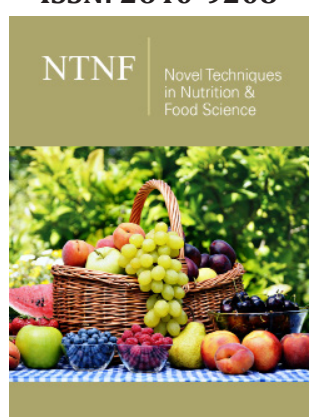

${ }^{* 1}$ Corresponding author: Bell SJ, Chief Science Officer, USA

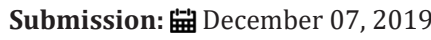

Published: 漈December 16, 2019

Volume 4 - Issue 4

How to cite this article: Wijendran V, Bauer K, Baker RA, Marsland C, Bell SJ. Dietary Intervention with NutrientDense, Portion-Controlled, Functional Foods Improve Blood Pressure in Adults. Nov Tech Nutri Food Sci. 4(4). NTNF.000594.2019.

DOI: 10.31031/NTNF.2019.04.000594

Copyright@ Bell SJ. This article is distributed under the terms of the Creative Commons Attribution 4.0 International License, which permits unrestricted use and redistribution provided that the original author and source are credited.

\author{
Wijendran $\mathrm{V}^{1}$, Bauer $\mathrm{K}^{1}$, Baker RA ${ }^{2}$, Marsland $\mathrm{C}^{3}$ and Bell SJ ${ }^{4 *}$ \\ ${ }^{1}$ Senior Clinical Research Associate, USA \\ ${ }^{2}$ Quality Control Quality Assurance Nutritionist, USA \\ ${ }^{3}$ Co-founder and Vice-Chairman, USA \\ ${ }^{4}$ Chief Science Officer, USA
}

\begin{abstract}
Background: Blood pressure (BP) is the major risk factor for cardiovascular diseases and is the leading cause of death in the US. The objective of this study was to determine the effectiveness of nutrient-dense, portion-controlled, functional foods coupled with E-nutrition counseling on BP in patients with hypertension.
\end{abstract}

Methods: Forty-one adults (17 males, 24 females) with a medical diagnosis of hypertension and elevated BP (BP>120/80 mm Hg) were recruited. Subjects consumed three nutrient-dense, portion-controlled, functional foods daily for 8 weeks. The foods included $25-35 \%$ of the Daily Value (DV) for all nutrients (including potassium) except for sodium and chloride. Systolic (SBP) and diastolic (DBP) BP and body weight were measured weekly by participants and self-reported. Quality of life was assessed using a validated questionnaire (SF-12), which measured physical (PCS) and mental (MCS) component scores.

Results: Baseline mean age, BMI and BP of study participants were $57 \pm 7$ years, $32.8 \pm 5.4 \mathrm{~kg} / \mathrm{m}^{2}$ and $146 \pm 18 / 89 \pm 8 \mathrm{~mm} \mathrm{Hg}$ SBP/DBP, respectively. BP decreased by $11.4 / 11.2 \mathrm{~mm} \mathrm{Hg}$ (SBP/DBP, $\mathrm{p}<0.05$ ) compared to baseline, after 8 weeks of the dietary intervention. Body weight and BMI decreased by $3.9 \%$ $(\mathrm{p}<0.05)$ and $1.7 \mathrm{~kg} / \mathrm{m}^{2}(\mathrm{p}<0.05)$, respectively. PCS and MCS scores improved $(\mathrm{p}<0.05)$ after 8 weeks of dietary intervention.

Conclusion: BP and body weight decreased significantly, and quality of life indicators improved after 8 weeks of a dietary intervention with nutrient-dense, portion-controlled, functional foods coupled with E-nutrition counseling. The improved BP reported in this study is comparable to Dietary Approaches to Stop Hypertension (DASH) diet and reported efficacy of anti-hypertensive drugs.

Keywords: Nutrient-dense foods; Functional foods; Blood pressure; Body weight; BMI; Quality of life

\section{Introduction}

Hypertension (HTN) is the major risk factor for cardiovascular diseases including stroke, myocardial infarction and heart failure [1]. It is the most common chronic condition affecting $46 \%$ of adults in the US [1,2]. The cost of treating hypertension is more than 50 billion dollars and continues to rise [3]. Even a modest decrease in blood pressure (BP) can significantly reduce the risk for stroke and cardio-vascular diseases [4]. Dietary modification and increased physical activity are the most important lifestyle intervention strategies recommended as the first line of treatment for elevated BP [2]. Among the dietary factors, it is well established that high sodium intake of $>4 \mathrm{~g} /$ day is associated with elevated BP [5,6]. Additionally, evidence shows that inadequate potassium intake was associated with elevated BP [5,7]. Clinical guidelines for BP management recommend limiting dietary sodium intake to $2.3 \mathrm{~g} /$ day or less and consuming adequate dietary potassium intake to meet the Daily Value (DV) of $4.7 \mathrm{~g} /$ day for adults to control BP [2]. Further, weight management is an important factor contributing to $\mathrm{BP}$ reduction $[2,8]$. 
To date, the Dietary Approaches to Stop Hypertension (DASH) diet is the most effective diet therapy for BP management and prevention of HTN $[2,9,10]$. The DASH diet is high in vegetables, fruits, whole grains, low-fat dairy, and limits saturated fats and high sodium foods [9]. While evidence clearly supports the benefits of diet therapy for BP control in patients at risk or with HTN, practitioners are not clear on the effectiveness of dietary modification as a treatment option for HTN. Furthermore, compliance with drug and diet therapy is generally less than optimal, with only $53 \%$ of adult patients with hypertension able to maintain BP control within the targeted range [2].

Dietary strategies to improve diet quality and compliance with BP management therapies are clearly needed. Functional foods improve diet quality and can be incorporated easily based on individual food preferences. These are foods enhanced with bioactive ingredients and have demonstrated health benefits [11]. Functional foods usually have demonstrated beneficial physiological effects in the prevention, management, and/or treatment of chronic disease. Functional foods can come from conventional foods, or from the addition of a bioactive constituent (e.g., vitamins or minerals) to conventional foods. Thus, nutrient-dense, functional foods with added essential nutrients that are inadequately consumed in the typical western diet (e.g., potassium, vitamin D and omega-3 fatty acids), can be an effective strategy to optimize BP management. The objective of the present study was to determine the effectiveness of a dietary intervention with nutrient-dense, portion-controlled, functional foods coupled with E-nutrition counseling based on DASH dietary guidelines on systolic and diastolic blood pressure and on quality of life in patients with HTN and/or elevated BP.

\section{Materials and Methods}

\section{Participants}

Adult men and women aged 50 years or older with a BP of greater than $120 / 80 \mathrm{~mm} \mathrm{Hg}$ were recruited using the social media platforms of Instagram and Facebook. Adults with hypertension related to congenital conditions and/or with a history of heart failure or stroke were excluded from the study.

\section{Study design}

In this interventional study, the participants consumed three nutrient-dense, portion-controlled, functional foods daily for 8 weeks. The packaged nutrient-dense foods were provided free of cost. Participants were encouraged to consume one snack and/or one meal of their own choice in addition to the three nutrient-dense foods, adhering to the DASH diet principles. Each week, participants measured BP and body weight, and completed a general quality of life questionnaire; this information was provided electronically to a HIPAA-compliant data collection storage site. At baseline, week 4 , and week 8, participants measured their waist circumference and completed the validated SF-12 quality of life questionnaire. E-nutrition counseling based on the American Heart Association's (AHA) recommended DASH dietary guidelines was provided weekly or as needed, free of charge.

\section{Diet}

Each nutrient-dense, portion controlled, functional food provided to the participants included 25-35\% DV for all essential nutrients, including potassium, vitamin D and other micronutrients, except for sodium and chloride; and $25 \%$ of the Adequate Intakes (AI) or more for omega-3 fatty acids. All foods were low in saturated fat and added sugar $(<10 \mathrm{~g} /$ serving). The nutrient content of the functional foods consumed (data not shown) was provided to the participants before starting the study.

\section{BP}

Participants self-measured morning and evening systolic (SBP) and diastolic BP (DBP) on two separate days each week using the BP monitor provided at no cost (Medline MDS 4001, Mundelin, IL) and self-reported weekly. Detailed written and video instructions for measuring BP were provided before the initiation of the study and additional assistance was provided by video conferencing, as needed. Most participants were familiar with self-monitoring BP.

\section{Anthropometrics}

Body weight was measured weekly and waist circumference was measured at baseline, weeks 4 and 8 , using a measuring tape provided free of charge, by the participant and self-reported. Disease risk for cardiovascular disease (CVD), hypertension, and type 2 diabetes was determined using body mass index (BMI) and waist circumference [12]. Waist circumference greater than $102 \mathrm{~cm}$ for men and $88 \mathrm{~cm}$ for women is classified as high risk for CVD [12].

\section{SF-12 questionnaire}

Participants completed the validated SF-12 questionnaire at baseline, weeks 4 and 8 . The SF-12 questionnaire tool was designed to assess quality of life in adults with hypertension [13]. This questionnaire measures eight domains on quality of life and provides two summary scores namely, physical component summary (PCS) and mental component summary scores (PCS). The SF-12 data compare the score of each participant against the mean score of the reference population. SF-12 questionnaire data was analyzed using Optum ${ }^{\circledR}$ SF-12v2 (Eden Prairie, MN).

\section{General Questionnaire}

Each week, participants answered questions about their quality of life. Questions probed were general feeling, fullness, mood, energy level, any gastrointestinal (GI) symptoms, sleep quality, appearance and overall diet quality. Each was rated using a scale of one to five, with 5 being the best and 1 being the worst. The percentage change between the mean at baseline and week 8 was calculated. Additionally, participants also provided information on the major foods consumed and physical activity weekly.

\section{E-Nutrition counseling}

E-nutrition counseling based on the AHA's recommended DASH dietary guidelines was provided by a registered dietitian nutritionist and/or a nutrition health coach via text, email, phone, or video conferencing weekly. Additionally, participants were provided individual counseling as needed. 


\section{Statistical analysis}

All data are expressed as mean \pm standard deviation. Data at baseline, week 4 and week 8 were used for analysis. Shapiro Wilk test was used to test the normality assumption. Changes in BP and quality of life indicators over 8 weeks were assessed by non-parametric Friedman repeated measures test and post-hoc Wilcoxon signed-rank test. Changes in anthropometric measures were analyzed using repeated measures analysis of variance and post-hoc paired t-test. Pearson correlation analysis was used to determine the correlation between change in body weight, waist circumference, and BP reduction after 8 weeks of intervention. Statistical analysis was performed using the IBM SPSS ${ }^{\varpi}$ software (IBM, Armonk, NY).

\section{Results}

Sixty eligible participants initially enrolled in the study, following rigorous pre-screening and $41(68 \%)$ of participants completed the study. Among the 19(32\%) who discontinued without completing the study, 5 were due to mild GI symptoms (gas, bloating), 3 were related to a hospitalization not related to the study, 1 was due to not liking the flavor/consistency of the nutrient dense foods, and 10 discontinued without communicating and giving a reason for discontinuing the study.

\section{Baseline characteristics}

The mean age of the study population was $57.1 \pm 6.0$ years (Table 1). The mean BMI was $32.8 \pm 5.4 \mathrm{~kg} / \mathrm{m}^{2}$, and $68 \%$ of participants were obese $\left(B M I \geq 30 \mathrm{~kg} / \mathrm{m}^{2}\right)$. The average BP (SBP/DBP) was $145.5 \pm 17.6 / 89.2 \pm 7.7 \mathrm{~mm} \mathrm{Hg}$. At baseline, 9 subjects $(22 \%)$ and $29(71 \%)$ had stage I and stage II HTN, respectively; and 73\% had one or more comorbidities: obesity, hyperlipidemia, arthritis and diabetes, which were the most prevalent comorbidities. Thirty-four (83\%) of participants were taking anti-hypertensive medications for BP control with nine on drug monotherapy and the rest on polytherapy.

Table 1: Background characteristics of study participants*.

\begin{tabular}{|c|c|}
\hline Number of participants completing the study & 41 \\
\hline Age (years) (mean \pm SD) & $57.1 \pm 6.0$ \\
\hline Gender & \\
\hline Males $\%(N)$ & $41 \%(17)$ \\
Females $\%(N)$ & $59 \%(24)$ \\
\hline Weight $(\mathrm{kg})(\mathrm{mean} \pm \mathrm{SD})$ & $93.0 \pm 17.9$ \\
\hline Body mass index $\left(\mathrm{BMI} ; \mathrm{kg} / \mathrm{m}^{2}\right)(\mathrm{mean} \pm \mathrm{SD})$ & $32.8 \pm 5.4$ \\
\hline BMI classification [\% and $(\mathrm{N})$ of participants] & $5 \%(2)$ \\
Normal $\left(<18.5 \mathrm{~kg} / \mathrm{m}^{2}\right)$ & $27 \%(11)$ \\
Overweight $\left(18.5-24.9 \mathrm{~kg} / \mathrm{m}^{2}\right)$ & $36 \%(15)$ \\
Obese I $\left(30.0-34.9 \mathrm{~kg} / \mathrm{m}^{2}\right)$ & $12 \%(8)$ \\
Obese II $\left(35.0-39.9 \mathrm{~kg} / \mathrm{m}^{2}\right)$ & $104.1 \pm 11.9$ \\
Obese III $\left(\geq 40 \mathrm{~kg} / \mathrm{m}^{2}\right)$ & $98.5 \pm 11.8$ \\
\hline Waist Circumference $(\mathrm{cm})\left(\mathrm{mean}^{2} \pm \mathrm{SD}\right)$ & \\
Males &
\end{tabular}

\begin{tabular}{|c|c|}
\hline $\begin{array}{c}\text { Increased disease risk based on Waist circumference } \\
{[\% \text { and }(\mathrm{N}) \text { of participants }]} \\
\text { Males }(>102 \mathrm{~cm}) \\
\text { Females }(>88 \mathrm{~cm})\end{array}$ & $\begin{array}{l}12 \%(5) \\
46 \%(19)\end{array}$ \\
\hline $\begin{array}{c}\text { Disease risk based on BMI and waist circumference } \\
\text { No risk } \\
\text { Increased } \\
\text { High } \\
\text { Very high } \\
\text { Extremely high }\end{array}$ & $\begin{array}{c}5 \%(2) \\
12 \%(5) \\
34 \%(14) \\
37 \%(15) \\
12 \%(5)\end{array}$ \\
\hline $\begin{array}{c}\text { Blood pressure }(\mathrm{BP}) \mathrm{mm} \mathrm{Hg}(\text { mean } \pm \text { SD }) \\
\text { Systolic BP** } \\
\text { Diastolic BP*** }\end{array}$ & $\begin{array}{c}145.5 \pm 17.6 \\
89.2 \pm 7.7\end{array}$ \\
\hline $\begin{array}{c}\text { BP risk status } \\
{[\% \text { and }(\mathrm{N}) \text { of participants }]} \\
\text { Normal }(<120 / 80 \mathrm{mmHg}) \\
\text { Elevated }(120-129 /<80 \mathrm{mmHg}) \\
\text { Stage I Hypertension }(130-139 / \mathrm{or} 80-89 \mathrm{mmHg}) \\
\text { Stage II Hypertension }(\geq 140 / \text { or } \geq 90 \mathrm{mmHg})\end{array}$ & $\begin{array}{l}0 \%(0) \\
7 \%(3) \\
22 \%(9) \\
71 \%(29\end{array}$ \\
\hline $\begin{array}{c}\text { Antihypertensive medications } \\
\text { Yes } \\
\text { No } \\
\end{array}$ & $\begin{array}{c}83 \%(34) \\
17 \%(7)\end{array}$ \\
\hline $\begin{array}{l}\text { Comorbidities \% (N) } \\
\text { Obesity } \\
\text { Diabetes } \\
\text { Hyperlipidemia } \\
\text { Arthritis } \\
\text { Asthma }\end{array}$ & $\begin{array}{c}68 \%(28) \\
15 \%(6) \\
36 \%(15) \\
24 \%(10) \\
7 \%(3)\end{array}$ \\
\hline
\end{tabular}

${ }^{*} \mathrm{~N}=41$;

**Average of morning and evening systolic blood pressure; $* * *$ Average of morning and evening diastolic blood pressure.

\section{Compliance}

$83 \%$ of participants reported excellent compliance consuming 3 nutrient-dense, functional foods daily as required by the dietary intervention protocol. $10 \%$ reported consuming two to three functional foods daily, and 7\% reported consuming 1 or none of the functional foods through the course of the study.

\section{Changes in BP}

Systolic and diastolic BP improved significantly $(\mathrm{p}<0.0001)$ after 8 weeks of dietary intervention with nutrient-dense functional foods and E-nutrition counseling compared to baseline (Table 2). Average BP (SBP/DBP) decreased significantly $(\mathrm{p}<0.001)$ by $8.8 / 7.4 \mathrm{~mm} \mathrm{Hg}$ after 4 weeks and decreased ( $\mathrm{p}<0.0001$ ) by $11.4 / 11.2 \mathrm{~mm} \mathrm{Hg}$ after 8 weeks of dietary intervention, compared to baseline (Figure 1). Overall, systolic and diastolic BP improved in $76 \%$ and $83 \%$ of the participants, respectively, after 8 weeks of dietary intervention. Changes in BP risk status is shown in Table 3. Percentage of participants with stage II hypertension declined from $71 \%$ at baseline to $27 \%$ after 8 weeks of dietary intervention. Among the participants who had stage II HTN at baseline, 32\% improved to stage I, 15\% improved to elevated, and $2 \%$ improved to normal. Additionally, among the participants who had stage I HTN at baseline, $5 \%$ improved to elevated and $2 \%$ improved to normal. 
Table 2: Changes in systolic and diastolic blood pressure (BP) at baseline, and 4 and 8 weeks after dietary intervention with nutrient-dense functional foods*.

\begin{tabular}{|c|c|c|c|}
\hline Blood Pressure (BP; mmHg) & Baseline & Week 4 & Week 8 \\
\hline Average Systolic BP** & $145.5 \pm 17.6^{\mathrm{a}}$ & $136.9 \pm 14.2^{\mathrm{b}}$ & $134.2 \pm 11.8^{\mathrm{b}}$ \\
\hline Morning Systolic BP & $146.7 \pm 20.0^{\mathrm{a}}$ & $137.1 \pm 15.7^{\mathrm{b}}$ & $134.7 \pm 14.0^{\mathrm{b}}$ \\
\hline Evening Systolic BP & $143.9 \pm 18.9^{\mathrm{a}}$ & $136.0 \pm 15.1^{\mathrm{b}}$ & $133.2 \pm 12.2^{\mathrm{b}}$ \\
\hline Average Diastolic BP*** & $89.2 \pm 7.7^{\mathrm{a}}$ & $81.8 \pm 8.5^{\mathrm{b}}$ & $78.0 \pm 9.0^{\mathrm{c}}$ \\
\hline Morning Diastolic BP & $90.6 \pm 7.8^{\mathrm{a}}$ & $82.1 \pm 8.0^{\mathrm{b}}$ & $78.8 \pm 10.2^{\mathrm{c}}$ \\
\hline Evening Diastolic BP & $87.7 \pm 10.0^{\mathrm{a}}$ & $81.5 \pm 10.4^{\mathrm{b}}$ & $77.1 \pm 8.9^{\mathrm{c}}$ \\
\hline
\end{tabular}

*Data are expressed as mean \pm standard deviation $(\mathrm{N}=41)$;

**Average of morning and evening systolic blood pressure;

***Average of morning and evening diastolic blood pressure;

a,b,cDifferent superscripts indicate significant difference $(p<0.05)$.

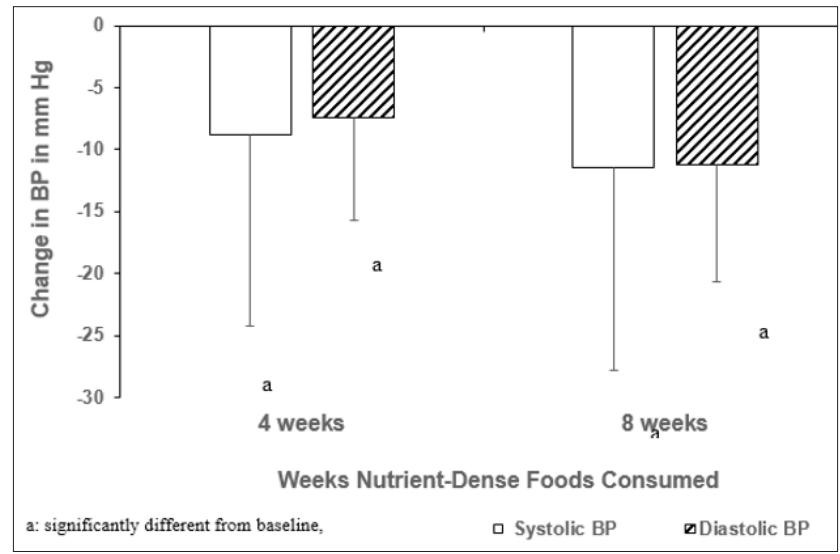

Figure 1: Blood pressure reduction after 4 and 8 weeks of dietary intervention with nutrient-dense functional foods, compared to baseline $(\mathrm{N}=41)$

Table 3: Changes in blood pressure (BP) risk status at baseline, and 4 and 8 weeks after dietary intervention with nutrient-dense functional foods*.

\begin{tabular}{|c|c|c|}
\hline $\begin{array}{c}\text { Blood Pressure Risk Status** } \\
\text { \% of Total (41) and (Number) of Participants }\end{array}$ & Baseline & Week 4 \\
\hline Normal (<120/80mmHg) & $0 \%(0)$ & $7 \%(3)$ \\
\hline Elevated (120-129/<80mmHg) & $7 \%(3)$ & $7 \%(3)$ \\
\hline $\begin{array}{c}\text { Stage I Hypertension } \\
(130-139 / \text { or 80-89mmHg) }\end{array}$ & $22 \%(9)$ & $42 \%(17)$ \\
\hline $\begin{array}{c}\text { Stage II Hypertension } \\
(\geq 140 / \text { or } \geq 90 \mathrm{mmHg})\end{array}$ & $71 \%(29)$ & $46 \%(19)$ \\
\hline
\end{tabular}

${ }^{*} \mathrm{~N}=41$;

**BP risk status was determined on 2017 ACC/AHA/AAPA/ABC/ACPM/AGS/APHA/ASH/ASPC/NMA/PCNA Guideline for the prevention, detection, evaluation, and management of high blood pressure in adults [2].

\section{Changes in anthropometrics}

Changes in body weight, BMI and waist circumference over 8 weeks of dietary intervention with nutrient-dense foods are shown in Table 4 . Body weight decreased ( $\mathrm{p}<0.00001)$ by $2.8 \%$ after 4 weeks and decreased $(\mathrm{p}<0.00001)$ by $3.9 \%$ after 8 weeks of dietary intervention. Mean BMI decreased $(\mathrm{p}<0.00001)$ by 1.6 units after 8 weeks of dietary intervention. Mean waist circumference changed significantly in females, after 4 weeks $(-4.2 \mathrm{~cm} ; \mathrm{p}<0.001)$ and 8 weeks $(-6.0 \mathrm{~cm} ; \mathrm{p}<0.001)$ of dietary intervention. In males, waist circumference did not change significantly over 8 weeks $(-2.4 \mathrm{~cm}$, 
NS). Disease risk based on BMI and waist circumference improved after 8 weeks of dietary intervention; notably, the percentage of participants at no disease risk increased from $5 \%$ at baseline to $15 \%$ after 8 weeks of dietary intervention. Weight loss was positively correlated with a reduction in average SBP $(\mathrm{R}=0.44$, $\mathrm{p}<0.01)$ and DBP $(\mathrm{R}=0.37, \mathrm{p}<0.05)$ at 8 weeks. The decrease in waist circumference over 8 weeks was positively correlated with a decrease in DBP $(R=0.39, p<0.05)$, but not with SBP $(R=0.30$, $\mathrm{p}=0.07$ ).

Table 4: Changes in body weight, body mass index (BMI) and waist circumference at baseline, and 4 and 8 weeks after dietary intervention with nutrient-dense functional foods*.

\begin{tabular}{|c|c|c|c|}
\hline Attributes & Baseline & Week 4 & Week 8 \\
\hline Body weight (kg) (mean \pm SD) & $93.0 \pm 17.9^{\mathrm{a}}$ & $90.4 \pm 17.5^{b}$ & $89.4 \pm 17.5^{c}$ \\
\hline Body weight change from baseline & & $-2.8 \%(-2.6 \mathrm{~kg})$ & $-3.9 \%(-3.6 \mathrm{~kg})$ \\
\hline BMI $\left(\mathrm{kg} / \mathrm{m}^{2}\right)($ mean $\pm \mathrm{SD})$ & $32.8 \pm 5.4^{\mathrm{a}}$ & $31.8 \pm 5.4^{\mathrm{b}}$ & $31.1 \pm 5.7^{c}$ \\
\hline $\begin{array}{c}\text { BMI classification } \\
{[\% \text { and }(\mathrm{N}) \text { of participants] }} \\
\text { Normal }\left(<18.5 \mathrm{~kg} / \mathrm{m}^{2}\right) \\
\text { Overweight }\left(18.5-24.9 \mathrm{~kg} / \mathrm{m}^{2}\right) \\
\text { Obese I }\left(30.0-34.9 \mathrm{~kg} / \mathrm{m}^{2}\right) \\
\text { Obese II }\left(35.0-39.9 \mathrm{~kg} / \mathrm{m}^{2}\right) \\
\text { Obese III }\left(\geq 40 \mathrm{~kg} / \mathrm{m}^{2}\right)\end{array}$ & $\begin{array}{l}5 \%(2) \\
27 \%(11) \\
36 \%(15) \\
20 \%(8) \\
12 \%(5)\end{array}$ & $\begin{array}{l}10 \%(4) \\
24 \%(10) \\
34 \%(14) \\
24 \%(10) \\
8 \%(3)\end{array}$ & $\begin{array}{l}15 \%(6) \\
27 \%(11) \\
27 \%(11) \\
24 \%(10) \\
7 \%(3)\end{array}$ \\
\hline $\begin{array}{l}\text { Waist Circumference }(\mathrm{cm})(\text { mean } \pm \text { SD }) \\
\text { Males } \\
\text { Females }\end{array}$ & $\begin{array}{l}104.1 \pm 11.9 \\
98.5 \pm 11.8^{\mathrm{a}}\end{array}$ & $\begin{array}{l}102.3 \pm 10.9 \\
94.3 \pm 11.9^{b}\end{array}$ & $\begin{array}{l}101.8 \pm 11.2^{2} \\
92.4 \pm 11.1^{\mathrm{c}}\end{array}$ \\
\hline $\begin{array}{c}\text { Increased disease risk based on waist circumference }(\mathrm{cm}) \\
{[\% \text { and }(\mathrm{N}) \text { of participants }]} \\
\text { Males }(>102 \mathrm{~cm}) \\
\text { Females }(>88 \mathrm{~cm})\end{array}$ & $\begin{array}{c}12 \%(5) \\
46 \%(19)\end{array}$ & $\begin{array}{c}10 \%(4) \\
42 \%(17)\end{array}$ & $\begin{array}{c}15 \%(6) \\
39 \%(16)\end{array}$ \\
\hline $\begin{array}{c}\text { Disease risk based on BMI and waist circumference** } \\
\text { No risk } \\
\text { Increased } \\
\text { High } \\
\text { Very high } \\
\text { Extremely high }\end{array}$ & $\begin{array}{l}5 \%(2) \\
12 \%(5) \\
34 \%(14) \\
37 \%(15) \\
12 \%(5)\end{array}$ & $\begin{array}{l}10 \%(4) \\
17 \%(7) \\
27 \%(11) \\
39 \%(16) \\
10 \%(4)\end{array}$ & $\begin{array}{l}15 \%(6) \\
20 \%(8) \\
17 \%(7) \\
39 \%(16) \\
7 \%(3)\end{array}$ \\
\hline
\end{tabular}

${ }^{*} \mathrm{~N}=41 ;$

**Disease risk for cardiovascular disease (CVD), hypertension, and type 2 diabetes was determined using body mass index (BMI) and waist circumference [12].

\section{Sf-12 questionnaire quality of life indicators}

Physical and mental component summary scores improved significantly at 4 weeks $(\mathrm{p}<0.04)$ and 8 weeks $(\mathrm{p}<0.002)$ after dietary intervention, compared to baseline scores (Table 5). The percentage of participants with physical component scores at or above the reference population benchmark increased to $80 \%$ at week 8 compared to $64 \%$ at baseline; those who were below the benchmark score at baseline decreased to $20 \%$ at week 8 compared to $35 \%$ at baseline. The percentage of participants with mental component scores at or above the reference population benchmark increased to $80 \%$ at week 8 compared to $60 \%$ at baseline; those who were below the benchmark score at baseline declined to $20 \%$ at week 8 compared to $40 \%$ at baseline.

\section{General Health Questionnaire Quality of Life Scores}

General quality of life scores at baseline, weeks 4 and 8 are presented in Table 6. Generally, the scores tended to improve for each quality of life indicator over the course of the study. Greatest improvements of at least $20 \%$ at 8 weeks compared to baseline were seen for diet quality (41\%), general feeling of wellness (39\%), energy level (35\%), and sleep (29\%). 
Table 5: SF-12 questionnaire physical and mental component scores at baseline, and 4 and 8 weeks after dietary intervention with nutrient-dense functional foods*.

\begin{tabular}{|c|c|c|c|}
\hline & Baseline & Week 4 & Week 8 \\
\hline Physical component summary score (mean \pm SD) & $44.7 \pm 11.4^{\mathrm{a}}$ & $47.5 \pm 11.7^{\mathrm{b}}$ & $49.1 \pm 11.3^{\mathrm{b}}$ \\
\hline $\begin{array}{c}\text { Physical functional status (\% of participants) } \\
\text { Above benchmark } \\
\text { At benchmark } \\
\text { Below benchmark }\end{array}$ & $\begin{array}{l}42 \\
22 \\
35\end{array}$ & $\begin{array}{l}63 \\
13 \\
24\end{array}$ & $\begin{array}{l}68 \\
12 \\
20\end{array}$ \\
\hline Mental component summary score (mean \pm SD) & $45.6 \pm 10.5^{\mathrm{a}}$ & $50.6 \pm 8.9^{\mathrm{b}}$ & $51.8 \pm 9.9^{b}$ \\
\hline $\begin{array}{l}\text { Mental functional status (\% of participants) } \\
\text { Above benchmark } \\
\text { At benchmark } \\
\text { Below benchmark }\end{array}$ & $\begin{array}{l}40 \\
20 \\
40\end{array}$ & $\begin{array}{l}61 \\
18 \\
21\end{array}$ & $\begin{array}{l}58 \\
22 \\
20\end{array}$ \\
\hline
\end{tabular}

${ }^{*} \mathrm{~N}=41$;

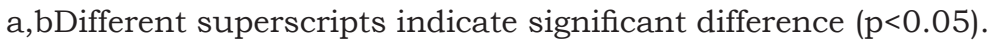

Table 6: General quality of life questionnaire scores at baseline, and 4 and 8 weeks after dietary intervention with nutrient-dense functional foods*.

\begin{tabular}{|c|c|c|c|}
\hline Attributes** & Baseline & Week 4 & Week 8 \\
\hline General feeling of wellness & $2.6 \pm 0.9$ & $3.4 \pm 0.9$ & $\begin{array}{c}3.6 \pm 0.9 \\
(39 \%)^{* * *}\end{array}$ \\
\hline Feel full & $3.1 \pm 0.7$ & $3.8 \pm 0.7$ & $\begin{array}{c}3.7 \pm 0.9 \\
(19 \%)^{* * *}\end{array}$ \\
\hline Mood & $3.8 \pm 1.0$ & $4.2 \pm 0.9$ & $\begin{array}{c}4.2 \pm 1.1 \\
(11 \%)^{* * *}\end{array}$ \\
\hline Energy level & $2.9 \pm 1.1$ & $3.8 \pm 0.9$ & $\begin{array}{c}3.9 \pm 1.0 \\
(35 \%)^{* * *}\end{array}$ \\
\hline GI symptoms & $3.7 \pm 1.0$ & $3.7 \pm 1.1$ & $\begin{array}{c}4.1 \pm 0.9 \\
(11 \%)^{* * *}\end{array}$ \\
\hline Sleep & $2.8 \pm 1.2$ & $3.6 \pm 0.9$ & $\begin{array}{c}3.6 \pm 1.0 \\
(29 \%)^{* * *}\end{array}$ \\
\hline Appearance & $3.1 \pm 0.9$ & $3.7 \pm 0.7$ & $\begin{array}{c}3.7 \pm 0.7 \\
(19 \%)^{* * *}\end{array}$ \\
\hline Diet quality & $2.7 \pm 0.9$ & $3.7 \pm 0.8$ & $\begin{array}{c}3.8 \pm 1.0 \\
(41 \%)^{* * *}\end{array}$ \\
\hline
\end{tabular}

*Data are expressed as mean \pm standard deviation $(\mathrm{N}=41)$;

**Each attribute was rated using a scale of one to five, with 5 being the best and 1 being the worst;

$* * *$ The percentage change between the mean at baseline and week 8 .

\section{Discussion}

This study demonstrated that including nutrient-dense, portion-controlled, functional foods in the diet of adults with hypertension or elevated BP can significantly reduce systolic and diastolic blood pressure. Additionally, significant weight loss and decreased BMI were observed. An important finding of this study was that health-related quality of life indicators namely, physical and mental component summary scores improved after 8 weeks from the dietary intervention.

Healthful dietary modification is currently recommended 
as the initial treatment, and as a complement to pharmacologic treatment for HTN [2]. Results from this study showed that dietary intervention with nutrient-dense, portion-controlled, functional foods, which provided about 75\% DV for essential nutrients including potassium daily, and E-health nutrition counseling based on DASH guidelines for 8 weeks, resulted in significant $\mathrm{BP}$ reduction of 11.4/11.2mm Hg (SBP/DBP). Furthermore, participants with stage II HTN benefitted the most as evidenced by a sharp decline in the number of participants with stage II HTN after 8 weeks of dietary intervention; only $27 \%$ of participants had stage II hypertension after 8 weeks of dietary intervention compared to $71 \%$ at baseline.

Previous studies $[9,10,14,15]$ have demonstrated the effectiveness of DASH intervention for treatment of HTN. A metaanalysis of 24 randomized clinical trials [14] revealed that DASH was the most effective dietary intervention, resulting in net reduction of systolic and diastolic BP by 7.6/4.2mm Hg, compared to control diet. Blumenthal et al. [10] showed that DASH coupled with weight management for 16 weeks resulted in a greater BP reduction of $16.1 / 9.9 \mathrm{~mm} \mathrm{Hg}$, compared to DASH alone, where BP reduction was $11.2 / 7.5 \mathrm{~mm} \mathrm{Hg}$ in adults with elevated or stage IHTN. The reported efficacy of anti-hypertensive drug therapies ranges from a net reduction of $10-16 \mathrm{~mm} \mathrm{Hg}$ for systolic and $8-10 \mathrm{~mm} \mathrm{Hg}$ for diastolic BP [16]. The BP reduction of 11.4/11.2mm Hg after 8 weeks of dietary intervention seen in this study is comparable to the reported effects of DASH with weight management and drug monotherapies. The magnitude of BP reduction observed in this study has been shown to lower stroke risk by $40 \%$ and cardiovascular disease risk by $25 \%$ [17].

Weight loss (4\% of baseline body weight) was likely an important factor contributing to the significant decrease in BP observed in this study. A previous study has also demonstrated that medically significant weight loss of at least $5 \%$ occurs with nutrient-dense foods [18]. The benefits of weight loss on BP control has been well documented $[2,8,10]$. A positive correlation between weight loss and reduction in systolic and diastolic BP after 8 weeks of dietary intervention seen in this study supports the importance of weight management in BP control interventions.

Improved diet quality, especially increased intake of dietary potassium with nutrient-dense foods, was likely another major factor contributing to the observed decrease in BP. Recent studies demonstrate that adequate dietary potassium intake and lower dietary sodium-to-potassium ratio effectively lower BP in hypertensive patients $[7,19]$. Current US dietary guidelines recommend daily intake of $4.7 \mathrm{~g} / \mathrm{d}$ potassium for adults [20], while WHO recommends at-least $3.5 \mathrm{~g} /$ day [21]. However, average intake of potassium in the U.S. is estimated to be between $2.5-2.7 \mathrm{~g} /$ day [5]. In this study, consuming three nutrient-dense foods provided at-least $75 \% \mathrm{DV}$, or $3.0 \mathrm{~g}$ /day potassium (77mmol/day) based on the potassium content of the nutrient-dense foods provided (data not shown). Furthermore, nutrition counseling based on DASH guidelines emphasized consuming a variety of vegetables and fruits daily, which would have also provided additional potassium.
Dietary sodium intake likely decreased during the study. Current clinical guidelines for BP management recommend restricting sodium to $2,000 \mathrm{mg} /$ day [2]. Sodium intake from the three nutrientdense foods would have provided a maximum of 2,000mg/day sodium ( $87 \mathrm{mmol} /$ day). While extreme sodium restriction was not emphasized in this study, a modest decrease in sodium intake based on DASH diet guidelines was expected. Current guidelines recommend a sodium-to-potassium ratio of 1.0-1.2 for optimal BP management [2]. However, dietary sodium-to-potassium ratio of the typical diet in the US is about 3.2 [5]. The estimated molar sodium-to potassium ratio from consuming the three functional foods was about 1.1 (maximal 2,000 $\mathrm{mg}$ or $87 \mathrm{mmol}$ sodium and at-least $3,000 \mathrm{mg}$ or $77 \mathrm{mmol}$ potassium from the three functional foods). Thus, the lower dietary sodium-to-potassium ratio was likely a significant factor underlying the observed BP reduction.

A significant finding of this study was improved health-related, quality of life assessed by SF-12 questionnaire of physical and mental component summary scores after 8 weeks of dietary intervention. Improved quality of life after dietary intervention was also supported by improved scores for general well-being, diet quality, energy level, and sleep. Impaired health-related, quality of life with lower physical and mental functional scores have been reported for hypertensive patients compared to normotensive population [22]. Further, hypertensive patients taking anti-hypertensive drugs for BP control had a worse quality of life compared to those not taking medications, resulting in lower adherence to pharmacotherapy [23]. Thus, our finding that the dietary intervention with nutrientdense functional foods and E-nutrition counseling significantly improved health-related quality of life has the potential to improve BP management in hypertensive adults.

The limitation of the study was that dietary intake was not assessed using validated tools such as urinary sodium and potassium excretion and diet recall. However, participants reported major foods consumed weekly and rated their diet quality. All data were self-measured and self-reported. However, no financial incentives were offered, thus minimizing participant bias in reporting their data. Results from this interventional study provide evidence that dietary intervention with nutrient rich, portioncontrolled, functional foods, coupled with E-health nutrition counseling, can be an effective treatment option for BP control in adults with HTN, including those with stage II HTN and using antihypertensive medications. Additionally, improved health-related quality of life parameters observed in adults with HTN after 8 weeks of dietary intervention is of clinical significance and needs further investigation.

\section{References}

1. Rapsomaniki E, Timmis A, George J, Rodriguez MP, Shah AD, et al. (2014) Blood pressure and incidence of twelve cardiovascular diseases: lifetime risks, healthy life-years lost, and age-specific associations in 1-25 million people. Lancet 383(9932): 1899-1911.

2. Whelton PK, Carey RM, Aronow WS, Casey DE, Collins KJ, et al. (2018) 2017 ACC/AHA/AAPA/ABC/ACPM/ AGS/ APhA/ASH/ASPC/ NMA/PCNA guideline for the prevention, detection, evaluation, and management of high blood pressure in adults: A report of the American 
college of cardiology/American heart association task force on clinical practice guidelines. Hypertension 71(6): e13-e115.

3. Davis KA (2010) Statistical brief \#404: expenditures for hypertension among adults age 18 and older, 2010: Estimates for the USA civilian noninstitutionalized population. Agency for Healthcare Research and Quality.

4. Gaciong Z, Siński M, Lewandowski J (2013) Blood pressure control and primary prevention of stroke: summary of the recent clinical trial data and meta-analyses. Curr Hypertens Rep 15: 559-574.

5. Jackson SL, Cogswell ME, Zhao L, Terry AL, Wang CY, et al. (2018) Association between urinary sodium and potassium excretion and blood pressure among adults in the United States: National health and nutrition examination survey, 2014. Circulation 137(3): 237-246.

6. Cook NR, Appel LJ, Whelton PK (2014) Lower levels of sodium intake and reduced cardiovascular risk. Circulation 129(9): 981-989.

7. Binia A, Jaeger J, Hu Y, Singh A, Zimmermann D (2015) Daily potassium intake and sodium-to-potassium ratio in the reduction of blood pressure: a meta-analysis of randomized controlled trials. J Hypertens 33: 1509-1520.

8. Fantin F, Giani A, Zoico E, Rossi AP, Mazzali G, Zamboni M (2019) Weight loss and hypertension in obese subjects. Nutrients 11: 1667.

9. Saneei P, Abargouei AS, Esmaillzadeh A, Azadbakht L (2014) Influence of dietary approaches to stop hypertension (dash) diet on blood pressure: a systematic review and meta-analysis on randomized controlled trials Nutr Metab Cardiovasc Dis 24: 1253-1261.

10. Blumenthal JA, Babyak MA, Hinderliter A, Watkins LL, Craighead L, et al. (2010) Effects of the DASH diet alone and in combination with exercise and weight loss on blood pressure and cardiovascular biomarkers in men and women with high blood pressure: the ENCORE study. Arch Intern Med 170(2): 126-135.

11. (2002) Archived-Policy Paper-Nutraceuticals/Functional Foods and Health Claims on Foods. Therapeutic Products Programme and the Food Directorate from the Health Protection Branch.

12. Classification of overweight and obesity by BMI, waist circumference, and associated disease risks. National Heart, Lung, and Blood Institute.
13. Schmidt S, Vilagut G, Garin 0 (2012) Reference guidelines for the 12item short form health survey version 2 based on the Catalan general population. Med Clin (Barc) 139: 613-625.

14. Gay HC, Rao SG, Vaccarino V, Ali MK (2016) Effects of different dietary interventions on blood pressure: systematic review and meta-analysis of randomized controlled trials. Hypertension 67(4): 733-739.

15. Appel LJ, Champagne CM, Harsha DW (2003) Writing Group of the PREMIER Collaborative Research Group. Effects of comprehensive lifestyle modification on blood pressure control: main results of the PREMIER clinical trial. JAMA 289: 2083-2093.

16. Law MR, Wald NJ, Morris JK, Jordan RE (2003) Value of low dose combination treatment with blood pressure lowering drugs: analysis of 354 randomized trials. BMJ 326: 1427.

17. Law MR, Morris JK, Wald NJ (2009) Use of blood pressure lowering drugs in the prevention of cardiovascular disease: meta-analysis of 147 randomized trials in the context of expectations from prospective epidemiological studies. BMJ 338: b1665.

18. Bell SJ, Ling PR, Marsland C (2016) Nutrient-dense, portion-controlled meals and snacks promote weight loss. J Food Technol Nutr Sci 2: 1-10.

19. Aburto NJ, Hanson S, Gutierrez H, Hooper L, Elliott P, et al. (2013) Effect of increased potassium intake on cardiovascular risk factors and disease: systematic review and meta-analyses. BMJ 346: f1378.

20. Dietary guidelines for Americans $2015-2020$ ( $\left.8^{\text {th }} \mathrm{edn}\right)$.

21. WHO (2012) Guideline: sodium intake for adults and children? World Health Organization (WHO), Geneva, Switzerland.

22. Trevisol DJ, Moreira LB, Kerkhoff A, Fuchs SC, Fuchs FD (2011) Healthrelated quality of life and hypertension: a systematic review and metaanalysis of observational studies. J of Hypertens 29: 179-188.

23. Trevisol DJ, Moreira LB, Fuchs FD, Fuchs SC (2012) Health-related quality of life is worse in individuals with hypertension under drug treatment: results of population-based study. J Hum Hypertens 26: 374-380.

For possible submissions Click below:

Submit Article 